\title{
Influence of selected (pre-)maturational parameters on in vitro development and sex distribution of bovine embryos $\dagger$
}

\author{
Eva Abele ${ }^{2,5}$, Hanna Stinshoff ${ }^{1,2,5}$, Ana Hanstedt ${ }^{2}$, Sandra Wilkening ${ }^{2}$, S. Meinecke-Tillmann ${ }^{3}$ \\ and Christine Wrenzycki ${ }^{2,4}$ \\ Clinic for Cattle; Department of Reproductive Biology; and Unit for Reproductive Medicine, University of Veterinary \\ Medicine Hannover, Germany
}

Date submitted: 21.12.2011. Date revised/accepted: 23.03.2012

\section{Summary}

\begin{abstract}
The objectives of this research were to study the influence of a reduced oxygen concentration during in vitro maturation (IVM) and examine the effect of follicular glucose concentration on bovine in vitro development and sex distribution. In the first experiment, abattoir-derived cumulus-oocyte complexes (COC) were matured under $5 \% \mathrm{O}_{2}$ or $20 \% \mathrm{O}_{2}$. Secondly, COC were isolated and the glucose $(\mathrm{G})$ concentration of each follicle was determined. COC were pooled in groups $\left(\mathrm{G}_{<1.1 \mathrm{mMol}}\right.$ or $\left.\mathrm{G}_{\geq 1.1 \mathrm{mMol}}\right)$ according to the glucose content before being subjected to in vitro production (IVP). Cleavage and development rates were assessed on days 3,7 and 8 post insemination. Blastocysts of each group were sexed by polymerase chain reaction (PCR). Expanded blastocysts were stained to assess total cell numbers and live-dead cell ratio. Cleavage and development rates stayed similar after reducing the $\mathrm{O}_{2}$ concentration during IVM. The sex ratio of embryos generated from oocytes matured under $5 \% \mathrm{O}_{2}$ was shifted in favour of the female (o: $61.9 \%$ ), whereas the sex ratio of embryos belonging to the IVM $20 \% \mathrm{O}_{2}$ group did not differ significantly from the expected 50:50 ratio. Neither a 'higher' nor a 'lower' intrafollicular glucose concentration influenced cleavage and development rates, cell numbers or livedead cell ratio. Eighty five per cent $\left(\mathrm{G}_{<1.1}\right)$ and $63.6 \%\left(\mathrm{G}_{\geq 1.1}\right)$ of the analysed embryos were female. In summary, neither a reduced $\mathrm{O}_{2}$ concentration during IVM nor selection based on follicular glucose concentrations affected the morphological quality of embryos. Although the sex distribution was shifted in favour of female embryos in all three experimental groups, more male embryos could be seen in the $\mathrm{G}_{\geq 1.1}$ group compared with the $\mathrm{G}_{<1.1}$ group.
\end{abstract}

Keywords: Development, Glucose, In vitro maturation, Oxygen, Sex distribution

\section{Introduction}

In vitro production (IVP) of bovine embryos has been improved immensely throughout the last decades. Nevertheless, embryos generated in vitro still differ

\footnotetext{
${ }^{1}$ All correspondence to: Hanna Stinshoff. KGGA, Frankfurter Str. 106, 35392 Giessen, Germany. Tel: +49 6419938742. Fax: +49 511856 7693. e-mail: hanna.stinshoff@vetmed.unigiessen.de

${ }^{2}$ Clinic for Cattle, University of Veterinary Medicine, Hannover, Germany.

${ }^{3}$ Department of Reproductive Biology, University of Veterinary Medicine Hannover, Germany.

${ }^{4}$ Unit for Reproductive Medicine, University of Veterinary

Medicine Hannover, Germany.

${ }^{5}$ Both authors contributed equally.

$\dagger$ Please cite as Abele, Stinshoff et al., 2012.
}

from their in vivo produced counterparts (Greve et al., 1994; Wrenzycki et al., 1998, 2007). It is possible to achieve blastocyst rates of up to $70 \%$ if in vivo matured oocytes are used. In contrast, if oocytes are matured in vitro, blastocyst rates are only half that of those matured in vivo (35\%; Rizos et al., 2002). In vitro culture (IVC) conditions have been enhanced in the last few years, mainly by adjustment of media formulations, whereas the in vitro maturation (IVM) seems to be invariable (for review see Sutton et al., 2003). Therefore, improvement of cumulus-oocyte complex (COC) selection as well as IVM might enhance the outcome of IVP.

Physiologically, the oxygen concentration in follicular fluid ranges between 3-13\% (McNatty, 1978), whereas the oxygen concentration employed in most IVM protocols is around 20\% (atmospheric oxygen 
concentration; Landau et al., 2000). In fact, no cells in intact mammals are exposed to an atmospheric oxygen concentration (Bavister, 1995). Thus, the gaseous environment to which the oocyte is exposed varies considerably between in vitro and in vivo conditions. The effect of employing a reduced oxygen concentration during IVM has been investigated in various species (hamster, Gwatkin \& Haidri, 1974; pig, Park et al., 2005; mouse, Preis et al., 2007) with contradictory results. In the bovine, a concentration of $5 \% \mathrm{O}_{2}$ during IVM was shown to have detrimental effects on maturation rates (Pinyopummintr \& Bavister, 1995). The reduced oxygen concentration also seems to have an impact on total cell numbers of blastocysts, increasing them in murine (Banwell et al., 2007; Preis et al., 2007) and bovine (Jiang et al., 1992) blastocysts. Nevertheless, using a reduced oxygen concentration while simultaneously supplementing the maturation medium with glucose led to increased consecutive blastocyst rates (Hashimoto et al., 2000a). This situation indicates a close connection between glucose and oxygen metabolism.

It is reported that the intrafollicular glucose concentration changes in dependency of the expansion and growth of the follicle (Wise, 1987). The glucose concentration also increases with increasing size of the follicle (Landau et al., 2000; Leroy et al., 2004). Regardless of this factor, other authors state that the intrafollicular glucose content does not vary in dominant or non-dominant bovine follicles throughout the estrous cycle (Orsi et al., 2005).

Matching these diverse results, the measured millimolar glucose concentrations vary vastly, for example ranging from $1.4-2.01 \mathrm{mM}$ in follicles with a diameter $<4 \mathrm{~mm}$ (Leroy et al., 2004; Sutton-McDowall et al., 2005). These discrepancies may be due partly to post-mortem effects that occur during transportation of ovaries from the abattoir to the laboratory. Despite the diverse reports on the intrafollicular glucose concentration, this concentration is always significantly lower than the blood glucose concentration (Leroy et al., 2004; Orsi et al., 2005). It has been suggested that an optimal glucose concentration in the maturation medium - similar to glucose concentrations in vivo - is elementary for a successful development up to the blastocyst stage. Insufficient or excessive glucose concentrations can diminish embryonic development (Hashimoto et al., 2000b).

The environmental conditions to which oocytes and early embryos are subjected in vitro - especially the glucose concentration - seem to be crucial for the sex ratio. Gender distribution is reported to be deferred towards the male by supplementing glucose to the medium. For IVC, a shift in the sex ratio towards the male could be detected if glucose was added to synthetic oviduct fluid (SOF) medium to a concentration of $5.56 \mathrm{mM}$ (Larson et al., 2001; Kimura et al., 2005). Several research groups have examined glucose as a possible physiological marker for sex distribution in mammalian offspring. A shift in the sex ratio could also be detected in embryos that had been cultured in SOF medium with $1.5 \mathrm{mM}$ glucose in contrast with a group of embryos cultured in SOF medium when the glucose had been substituted with citrate and myo-inositol. Here, significantly, more male embryos developed in the SOF-glucose group (Rubessa et al., 2011).

Therefore, the present study was conducted to investigate the effects of an oxygen tension of 5\% during IVM (Experiment 1). Secondly, it was examined whether measuring the follicular glucose concentration (Experiment 2) prior to IVM allows conclusions regarding development, morphological quality and sex distribution of bovine embryos generated from these cumulus-oocyte complexes, thus possibly presenting a new selection parameter for COC used in IVP.

\section{Materials and methods}

Unless otherwise stated all chemicals were obtained from Sigma (Steinheim, Germany).

\section{Cumulus-oocyte complex collection}

Bovine ovaries were obtained from a local abattoir and transported into the laboratory in Dulbecco's phosphate-buffered saline (PBS). Complete (PBS supplemented with $11.2 \mathrm{mg} / 1$ heparin and $1.0 \mathrm{~g} / 1$ bovine serum albumin (BSA)) at $37^{\circ} \mathrm{C}$ within $4 \mathrm{~h}$ of slaughter. The ovaries were washed three times with $0.9 \%$ sodium chloride $(\mathrm{NaCl})$ solution that contained $0.06 \mathrm{~g} \mathrm{l}^{-1}$ penicillin and $0.01 \mathrm{~g}^{-1}$ streptomycin. Cumulus-oocyte complexes (COC) were isolated using the slicing method described previously by Eckert \& Niemann (1995). The selection of COC was performed under a stereomicroscope according to morphological criteria. Only those complexes deemed suitable (Kastrop et al., 1990) were pooled in tissue culture media (TCM) air (1.51 mg TCM199, $5 \mathrm{mg}$ gentamycin, $2.2 \mathrm{mg}$ sodium pyruvate, $35 \mathrm{mg} \mathrm{NaHCO}$, $100 \mathrm{ml}$ sterile water [Ampuwa $\AA$, Fresenius, Bad Homburg, Germany], 100 mg BSA) and used for IVM.

\section{Follicle dissection and measurement of follicular glucose concentration}

A total of 240 individual follicles with a diameter of $>3 \mathrm{~mm}$ were isolated individually from ovaries of the same origin as stated above. The procedure was performed on a hot plate at $37^{\circ} \mathrm{C}$ using a scalpel 
and surgical forceps. During the process of follicle dissection, the follicle surface was kept moist with PBS Complete medium. The outer diameter of each follicle was measured and ruptured carefully to release the follicular fluid and the COC. Follicular glucose concentration was determined using a blood glucose metre (Freestyle Freedom Lite, Abbott, Wiesbaden, Germany). Afterwards, COC were allocated to two groups according to their individual follicular glucose concentration: $G_{<1.1}$ for $<1.1 \mathrm{mM}$ and $G_{\geq 1.1}$ for $\geq 1.1 \mathrm{~mm}$. COC were then treated as described above.

\section{In vitro production}

Embryos were generated as described recently (Stinshoff et al., 2011) according to a standard protocol. Briefly, COC ( $n=20 /$ drop) were placed in $100-\mu 1$ droplets of maturation medium $(0.453 \mathrm{~g}$ TCM199 supplemented with $1.5 \mathrm{~g}$ gentamicin sulphate; $0.66 \mu \mathrm{g}$ sodium pyruvate; $0.066 \mathrm{mg} \mathrm{NaHCO}_{3}$; $0.3 \mathrm{~g}$ BSA fatty acid free (FAF), dissolved in $30 \mathrm{ml}$ sterile water [Ampuwa $\AA$, Fresenius, Bad Homburg, Germany]) and $25 \mu \mathrm{l}$ suigonan (10 IU ml $\mathrm{IU}^{-1} \mathrm{eCG}$ [equine chorionic gonadotropin] and $5 \mathrm{IU} \mathrm{ml}^{-1} \mathrm{hCG}$ [human chorionic gonadotropin]) under silicon oil for in vitro maturation (IVM). Maturation was carried out for $24 \mathrm{~h}$ at $39^{\circ} \mathrm{C}$ in an humidified atmosphere under $5 \% \mathrm{O}_{2}, 5 \% \mathrm{CO}_{2}$ or under atmospheric $(\sim 20 \%) \mathrm{O}_{2}$ conditions and $5 \% \mathrm{CO}_{2}$ (control group, $\mathrm{G}_{<1.1}, \mathrm{G}_{\geq 1.1}$ ).

For IVF (in vitro fertilization), matured COC were rinsed in fertilization medium (Fert-TALP Tyrode's albumin lactate pyruvate supplemented with $6 \mathrm{mg} \mathrm{ml}^{-1}$ BSA) and placed in 100- $\mu$ l droplets of Fert-TALP (supplemented with $10 \mu \mathrm{M}$ hypotaurine, $1 \mu \mathrm{M}$ epinephrine, $0.1 \mathrm{IU} / \mathrm{ml}$ heparin and $6 \mathrm{mg} \mathrm{ml}^{-1}$ BSA) in groups of 20. Bull semen with proven IVF fertility was thawed in a water bath at $30^{\circ} \mathrm{C}$ for $10 \mathrm{~s}$ and then centrifuged for $16 \mathrm{~min}$ at $380 \mathrm{~g}$ with a $90 \%$ gradient of Sperm Filter $\AA$ (Gynemed, Lensahn, Germany). The supernatant was discarded, the remaining semen pellet was resuspended in $750 \mu \mathrm{l}$ Fert-TALP-solution and centrifuged ( $380 \mathrm{~g}$ for $3 \mathrm{~min}$ ). The supernatant was discarded leaving $50 \mu \mathrm{l}$. The pellet was resuspended in $750 \mu \mathrm{l} \mathrm{HHE}$ (hypotaurine heparin epinephrine) and centrifuged for $3 \mathrm{~min}$ at $380 \mathrm{~g}$. In the last step, the supernatant was removed leaving $100 \mu l$ of sperm solution. A final concentration of 100,000 spermatozoa per $100 \mu \mathrm{l}$ Fert-TALP/HHE was co-incubated in vitro with the $\mathrm{COC}$ for $19 \mathrm{~h}$ at $39^{\circ} \mathrm{C}$ in a humidified atmosphere and $5 \% \mathrm{CO}_{2}$ in air.

Subsequently, for IVC, presumptive zygotes were transferred into TCM air. Adherent cumulus cells were removed completely by repeated pipetting using a micropipette (diameter: $125 \mu \mathrm{m}$ or $135 \mu \mathrm{m}$, respectively). SOFaa (Holm et al., 1999) supplemented with $4 \mathrm{~g} \mathrm{l}^{-1}$ BSA (FAF) was used as medium for
IVC. Presumptive zygotes were placed in drops of culture medium in groups of six and cultivated at $39^{\circ} \mathrm{C}$ under $5 \% \mathrm{O}_{2}, 5 \% \mathrm{CO}_{2}$. Cleavage and development rates of the embryos were assessed on days 3,7 and 8 post insemination (pi; day $0=$ IVF) as means of morphological quality evaluation. Embryos that had reached either the stage of blastocysts, expanded blastocysts or hatched blastocysts on day 8 p.i. were washed in PVA and stored individually at $-80^{\circ} \mathrm{C}$ until used for sex determination.

\section{Total cell number and live-dead ratio}

Only embryos that had reached the stage of an expanded blastocyst on day 8 p.i. were used for the cell count. The embryos were washed three times in a PBS $+0.1 \%$ polyvinylalcohol (PVA) solution and incubated for $15 \mathrm{~min}$ in $0.01 \%$ ethidium homodimer (Invitrogen, Karlsruhe, Germany) under exclusion of light. Ethidium homodimer is not able to pass intact cell membranes and thus only stains dead cells. Subsequently, blastocysts were incubated for $3 \mathrm{~min}$ in PBS + 0.002\% Hoechst bisbenzimide 33342 (Invitrogen, Germany). In contrast to ethidium homodimer, the Hoechst stain is able to pass intact cell membranes and stains live cells blue. Stained expanded blastocysts were pipetted on an object slide and covered with a coverslip. The total cell number was counted using a fluorescence microscope (Olympus, Hamburg, Germany) at $\times 20$ magnification. In addition the livedead cell ratio was determined.

\section{Sex determination of the embryos}

Embryos $\left(5 \% \mathrm{O}_{2}: n=21 ; 20 \% \mathrm{O}_{2}: n=20 ; \mathrm{G}_{<1.1}: n=\right.$ 20; $\mathrm{G}_{\geq 1.1}: n=22$ ) were chosen randomly for sexing via PCR. For PCR, as described previously by Morton et al. (2007), embryos were diluted in $11 \mu$ l sterile water (Ampuwa, Germany). Preparation for PCR employed three steps: $5 \mathrm{~min}$ at $95^{\circ} \mathrm{C}$ followed by $2 \mathrm{~min}$ on ice and again $5 \mathrm{~min}$ at $95^{\circ} \mathrm{C}$. Samples were centrifuged (16100 $g$; Biofuge Fresco, Haereus, Hanau, Germany) and kept on ice. PCR was performed in a final volume of $50 \mu \mathrm{l}$ (1× PCR buffer, $25 \mathrm{mM} \mathrm{MgCl} 2,20 \mathrm{mM}$ of each dNTP, $10 \mu \mathrm{M}$ of the bovine-specific primer [see Table 1], $10 \mu \mathrm{M}$ of the Y-specific primer [see Table 1] and $5 \mathrm{U} / \mu \mathrm{l} \mathrm{Taq}$ polymerase). The PCR program employed an initial step of $97^{\circ} \mathrm{C}$ for $2 \mathrm{~min}$ followed by 35 cycles each of $30 \mathrm{~s}$ at $95^{\circ} \mathrm{C}$ for denaturation, $30 \mathrm{~s}$ at $60^{\circ} \mathrm{C}$ for annealing of primers and $30 \mathrm{~s}$ at $72^{\circ} \mathrm{C}$ for primer extension. The last cycle was followed by a $5 \mathrm{~min}$ extension at $72^{\circ} \mathrm{C}$ and cooling to $4^{\circ} \mathrm{C}$. PCR products were subjected to electrophoresis on a $4 \%$ agarose gel and visualized under a UV lamp. 
Table 1 Specific primers used for polymerase chain reaction (PCR)

\begin{tabular}{llc}
\hline & \multicolumn{1}{c}{ Sequence } & Length (bp) \\
\hline Bovine specific & F: AGGTCGCGAGATTGGTCGCTAGGTCATGCA & 300 \\
Y-chromosome specific & $\begin{array}{l}\text { R: AAGACCTCGAGAGACCCTCTTCAACACGT } \\
\text { F: CCTCCCCTTGTTCAAACGCCCGGAATCATT } \\
\text { R: TGCTTGACTGCAGGGACCGAGAGGTTTGGG }\end{array}$ & 210 \\
\hline
\end{tabular}

\section{Experimental design}

\section{Experiment 1}

In the first experiment COC were divided randomly into two groups. Those assigned to the first group were matured in an oxygen deprived atmosphere (5\% $\mathrm{O}_{2}$ IVM group). The COC of the control group were matured under atmospheric conditions. IVF and IVC were performed as described above. Cleavage rates on day 3 pi, developmental rates on days 7 and 8 pi, total cell number and live-dead cell ratio, as well as the sex on day 8 p.i. of embryos that had reached the stage of an expanded blastocyst were determined.

\section{Experiment 2}

In the second experiment follicles were isolated from ovaries and COC pooled according to the glucose content of the originating follicle and employed in IVP. Morphological quality was assessed by determining cleavage rates on day 3 p.i. and development rates on days 7 and 8 pi. Total cell numbers, live-dead cell ratio and sex ratio were analysed in embryos that had reached the stage of an expanded blastocyst on day 8 p.i. according to the above mentioned protocols.

\section{Statistical analysis}

Evaluation of cell numbers and ratio of live and dead cells was performed via variance analysis followed by multiple pair wise comparisons using the Tukey test. Distribution of embryonic sex was determined using chi-squared analyses. A $P$-value $\leq 0.05$ was considered to be statistically significant.

\section{Results}

\section{Experiment 1}

In total, $540 \mathrm{COC}$ were matured under an oxygen concentration of $5 \%$ and 519 COC under atmospheric oxygen concentration. The subsequent cleavage (day 3 p.i.) and development rates (day 7 p.i. and day 8 p.i.) did not differ significantly between the two groups (Table 2).

Neither the total cell number nor the live-dead cell ratio of expanded blastocysts differed significantly (Table 2).
Table 2 Effect of oxygen tension during in vitro maturation on bovine embryo development, total cell number and ratio of live and dead cells in expanded blastocysts matured under different oxygen concentrations

\begin{tabular}{lrr}
\hline & \multicolumn{1}{c}{$\begin{array}{c}\text { Control } \\
\text { group }\end{array}$} \\
& $5 \% \mathrm{O}_{2}$ IVM & \multicolumn{1}{c}{$\left(20 \% \mathrm{O}_{2}\right)$} \\
\hline Cleavage rate day 3 pi* $\left.^{*} \%\right)$ & $57.5 \pm 4.0$ & $57.3 \pm 2.9$ \\
Developmental rate day 7 pi* (\%) & $21.5 \pm 2.4$ & $19.4 \pm 2.8$ \\
Developmental rate day 8 pi* (\%) & $26.6 \pm 2.8$ & $22.6 \pm 2.3$ \\
Total cell number* & $109.0 \pm 3.6$ & $108.7 \pm 3.4$ \\
Ratio of live and dead cells* & $24.6 \pm 6.3$ & $28.5 \pm 4.2$ \\
\hline
\end{tabular}

${ }^{*}$ Mean \pm standard deviation (SD); IVM, in vitro maturation; pi, post insemination.

Table 3 Sex distribution of bovine embryos matured under $5 \% \mathrm{O}_{2}$ or atmospheric oxygen concentration

\begin{tabular}{lcc}
\hline & $\begin{array}{c}5 \% \mathrm{O}_{2} \text { IVM } \\
(n=21)(\%)\end{array}$ & $\begin{array}{c}\text { Control group }\left(20 \% \mathrm{O}_{2}\right) \\
(n=20)(\%)\end{array}$ \\
\hline$q(\mathrm{XX})$ & $61.9^{a}(n=13)$ & $55.0^{a}(n=11)$ \\
$\sigma^{a}(\mathrm{XY})$ & $38.1^{b}(n=8)$ & $45.0^{a}(n=9)$ \\
\hline$a, b p \leq 0.05$ within column. IVM, in vitro maturation.
\end{tabular}

The distribution of sexes among embryos showed a significant shift towards the female in those embryos that developed of COC matured under restricted oxygen conditions (Table 3 ) in comparison with the expected ratio of $50: 50 \%$. A representative gel photo of PCR results is shown in Fig. 1.

\section{Experiment 2}

In total, 117 COC were isolated from follicles with an intrafollicular glucose concentration of $<1.1 \mathrm{mM}$. Employing the same method, 123 COC were obtained from follicles with a glucose content of $\geq 1.1 \mathrm{mM}$. Cleavage (day 3 p.i.) and development rates on day 7 and on day 8 p.i. did not differ significantly between the two groups (Table 4 ).

Total cell number $(107.4 \pm 5.6$ vs. $111.3 \pm 5.2)$ and live-dead cell ratio ( $26.8 \pm 4.1$ vs. $26.6 \pm 4.6)$ of expanded blastocysts did not differ significantly between the two groups (Table 4). 


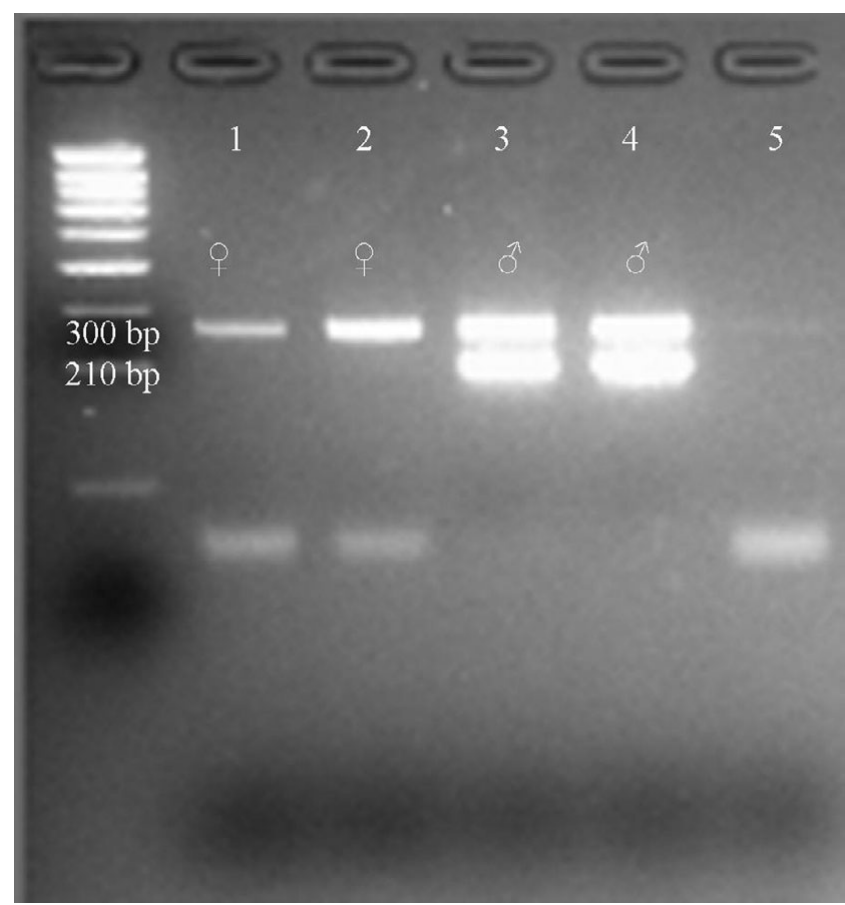

Figure 1 Representative gel photo (4\% agarose gel) of analysis of sex distribution of bovine embryos: (1) female embryo, (2) control for 'female,' (3) male embryo, (4) control for 'male'.

Table 4 Effect of follicular glucose content on bovine embryo development and total cell number and ratio of live and dead cells of expanded blastocysts from groups $\mathrm{G}_{<1.1}$ and $\mathrm{G}_{\geq 1.1}$

\begin{tabular}{lrr}
\hline & $\begin{array}{c}\mathrm{G}_{<1.1} \\
(<1.1 \mathrm{mM})\end{array}$ & \multicolumn{1}{c}{$\begin{array}{c}\mathrm{G}_{\geq 1.1} \\
(\geq 1.1 \mathrm{mM})\end{array}$} \\
\hline Cleavage rate day 3 pi* $(\%)$ & $81.8 \pm 4.7$ & $79.3 \pm 4.9$ \\
Developmental rate day 7 $\mathrm{pi}^{*}(\%)$ & $35.6 \pm 5.2$ & $31.6 \pm 5.2$ \\
Developmental rate day 8 pi* $\left.^{*} \%\right)$ & $47.0 \pm 6.4$ & $49.4 \pm 6.7$ \\
Total cell number* & $107.4 \pm 5.6$ & $111.3 \pm 5.2$ \\
Ratio of live and dead cells* & $26.8 \pm 4.1$ & $26.6 \pm 4.6$ \\
\hline
\end{tabular}

${ }^{*}$ Mean \pm standard deviation (SD); pi = post insemination.

Table 5 Sex distribution of bovine embryos from groups $\mathrm{G}_{<1.1}$ and $\mathrm{G}_{\geq 1.1}$

\begin{tabular}{lcc}
\hline & $\mathrm{G}_{<1.1}(n=20)(\%)$ & $\mathrm{G}_{\geq 1.1}(n=22)(\%)$ \\
\hline q (XX) & $85.0^{a}$ & $63.6^{a}$ \\
o $^{a}(\mathrm{XY})$ & $15.0^{b}$ & $36.4^{b}$ \\
\hline
\end{tabular}

${ }_{a, b} p \leq 0.05$ within column.

The sex distribution of embryos of both groups differed significantly from the expected distribution of 50:50. In both groups more female embryos $\left(G_{<1.1}\right.$ : $85.0 \%$ female vs. $15 \%$ male embryos and $G_{\geq 1.1}: 63.6 \%$ female vs. $26.4 \%$ male) could be observed (Table 5).

\section{Discussion}

The aim of maturation systems in vitro is to supply the oocyte with a suitable environment to resume and complete meiosis, finally reaching the second metaphase stage. There is a wide range of available protocols for this specific step in IVP. van de Sandt et al. (1990) showed that the use of different maturation media resulted in differences in preimplantation development in murine embryos. This observation has been verified in the bovine (Rose \& Bavister, 1992). Initially, TCM199 proved to be a suitable basis for a maturation medium, resulting in good quality embryos. Nevertheless, it was not originally designed for IVM but for somatic cell culture (Morgan et al., 1950, 1955). Other media employed in IVM include a modified SOF medium (de Castro \& Hansen, 2007). Alterations in protocols have gone as far as the use of a two-step maturation protocol with a period of meiosis inhibition prior to the final maturational step (Pavlok et al., 2005).

Subsequent embryo development rates are known to differ vastly with regards to the employed media in each step of IVP. At present, the final culture step is mostly conducted in oxygen-reduced conditions, which are considered to be beneficial to successive development rates (Thompson et al., 1990). Interestingly, there is no consent about the influence of a reduced oxygen concentration during maturation on the subsequent development of embryos. The obtained results differ vastly, possibly due to the varying media employed. Apart from offering an explanation for the controversial results this fact also inhibits a direct comparison.

Interactions between oxygen concentration and the employed media have been shown. Especially in TCM199-based medium, the oxygen concentration is a determinant of development to the blastocyst stage (de Castro \& Hansen, 2007). Furthermore, it was possible to link the glucose concentration in the employed media in combination with the oxygen concentration to alterations in subsequent embryo development. It has been suggested that in a static in vitro system, as used for maturation, employed media should contain a supra-physiological glucose concentration in order to supply enough glucose at all times during maturation (Sutton-McDowall et al., 2010). A glucose concentration similar to that of the follicular glucose concentrations in vivo in the maturation medium is needed to show effects induced by a reduced oxygen tension - visible in increased developmental rates (Hashimoto et al., 2000b). The employed glucose concentration in the present work was $5.6 \mathrm{mM}$. The lack of distinctions regarding cleavage and development rates may be because this concentration could be too low to evoke effects in 
combination with a reduced oxygen concentration during IVM.

Staining of expanded blastocysts revealed no significant difference in total cell numbers between the $5 \% \quad \mathrm{O}_{2} \quad$ IVM group and the control group. There are also controversial results in total cell numbers of blastocysts among studies, reflecting the diverse effects of different oxygen concentrations on embryo development. Total cell numbers of bovine (Oyamada \& Fukui, 2004), porcine (Kikuchi et al., 2002; Iwamoto et al., 2005; Karja et al., 2006) and murine blastocysts (Preis et al., 2007) were increased if oocytes were matured previously under reduced oxygen tension. Nevertheless, a different study conducted in the porcine also detected no effect on total cell numbers (Park et al., 2005). Additionally, staining allowed differentiation between live and dead cells, and allowed evaluation of the injuriousness of a method, as determined by the live-dead cell ratio. No differences could be detected in the present study regarding this parameter, reinforcing the assumption that, under the present conditions, a reduction of the oxygen concentration during IVM neither impairs nor improves subsequent embryonic development.

Differences in development between female and male embryos, such as in speed of development, arise in the disproportionate expression of sex-specific genes or genes that are regulated by X-chromosomal transcripts (reviewed by Gutierrez-Adan et al., 2006). For the first time, we were able to describe the effect of a reduced oxygen concentration during IVM on subsequent gender distribution of the embryos. In the present study, significantly more female embryos were generated from oocytes that had been matured previously under $\mathrm{O}_{2}$-reduced conditions. The sex shift among embryos of the control group did not differ significantly from the expected 1:1 ratio (Gamarra et al., 2011; Table 2). These results seem to be controversial when compared with studies conducted earlier. Here it was discussed that oocytes that were matured under a higher oxygen concentration contained an increased amount of reactive oxygen species (ROS; Hashimoto 2009). The amount is regulated by glucose6-phosphate dehydrogenase (G6PD; Filosa et al., 2003) - the gene of which is located on the $X$ chromosome (Gutierrez-Adan et al., 2000). Accordingly, it would seem to be more likely to expect that a larger number of female embryos originated from oocytes that had been matured under atmospheric oxygen conditions. This proposal is supported by the results of Iwata et al., (2002), which showed a higher developmental competence for embryos with higher G6PD activity under stress conditions, e.g. high oxygen concentrations. However, these results were obtained by the analysis of early embryos and with regards to the early embryos' environment and not to that of the oocyte. An analysis of obtained embryos at the molecular level will be necessary to clarify the arisen discrepancies.

Cleavage and development rates between embryos generated with oocytes from follicles with defined glucose levels $(<1.1 \mathrm{mM}$ and $\geq 1.1 \mathrm{mM})$ did not differ significantly.

Interestingly, cleavage and development rates obtained in this experiment are higher than those obtained in Experiment 1, even though IVP was performed in the same laboratory. A possible explanation may lie in the different handling of ovaries at the time of COC collection. As follicle dissection is more time consuming than the slicing method a so-called 'postmortem' effect may have occurred. The duration of storage after slaughter has a subsequent effect on the development of embryos. A storage duration of $4 \mathrm{~h}$ after slaughter resulted in the highest development rates on day $7 \mathrm{pi}$, compared with either a shorter or a longer storage time (Blondin et al., 1997). Additionally, the time for handling of oocytes and zygotes during IVF or IVC steps was shortened on account of the restricted number of oocytes isolated individually from their follicles.

So far, the effects of intrafollicular glucose concentrations in premature follicles on subsequent embryo development have not been studied, whereas the effects of differing glucose concentrations during IVM have been studied in varying species, including the bovine (Rose-Hellekant et al., 1998; Khurana \& Niemann, 2000; Sutton-McDowall et al., 2005; Herrick et al., 2006). In conjunction with other results, it is possible to link glucose supplementation during IVM to an increase in total cell numbers in caprine blastocysts (Sato et al., 2007).

Staining of expanded or hatched blastocysts of groups $\mathrm{G}_{<1.1}$ and $\mathrm{G}_{\geq 1.1}$ showed no significant differences in the total cell number and the live-dead cell ratio between the two groups in the present study, a finding that indicated that embryos of both groups were of similar quality.

There is growing evidence for a maternal influence on sex distribution of offspring mediated through testosterone concentration and glucose availability (reviewed by Grant \& Chamley, 2010). Sex analysis of embryos of the groups $G_{<1.1}$ and $G_{\geq 1.1}$ showed a significant alteration from the expected distribution of 50:50 (Gamarra et al., 2011; Table 4). It is suggested that glucose supplementation produces a preferential loss of female embryos during culture (Gutierrez-Adan et al., 2001) whereas the presence of glucosamines during maturation did not affect the sex ratio of bovine IVP-derived embryos (Kimura et al., 2008). In the present study, the oocytes were pooled according to the glucose content of their originating follicles. Although a shift towards the female could be detected 
in both groups, an increase in male embryos generated from the oocytes of the $G_{\geq 1.1}$ group was seen. In other species it has been proposed that a high maternal blood glucose concentration is related to male-biased litters (Mus musculus and Microtus agrestis: Rosenfeld et al., 2003; Helle et al., 2008).

It has been suggested that glucose plays an important role in the final maturational phase of the oocytes. An excessive glucose concentration $(20 \mathrm{mmol})$ during IVP has detrimental effects on the embryos development just as well as COC matured in a glucose-deprived medium (Hashimoto et al., 2000b). Here, fewer oocytes were able to reach metaphase II than oocytes cultured in media supplemented with physiological glucose concentrations.

The results of this work indicate that, under the present conditions, a reduced oxygen concentration during IVM - although not affecting in vitro development or morphological quality - shifts the sex ratio of bovine embryos towards the female.

Additionally, we were able to show that with high(er) follicular glucose concentrations, an increase in the number of male embryos may be obtained. This result shows that the glucose concentration of the oocyte's environment plays a crucial role in gender distribution even before the final maturational stage is reached.

\section{Acknowledgements}

The authors would like to thank Doris Mueller for her assistance in the IVP laboratory.

\section{References}

Banwell, K.M., Lane, M., Russell, D.L., Kind, K.L. \& Thompson, J.G. (2007). Oxygen concentration during mouse oocyte in vitro maturation affects embryo and fetal development. Hum. Reprod. 22, 2768-75.

Bavister, B.D. (1995). Culture of preimplantation embryos: facts and artifacts. Hum. Reprod. Update 1, 91-148.

Blondin, P., Coenen, K., Guilbault, L.A. \& Sirard, M.A. (1997). In vitro production of bovine embryos: developmental competence is acquired before maturation. Theriogenology 47, 1061-75.

de Castro, E.P.L.A. \& Hansen, P.J. (2007). Interactions between oxygen tension and glucose concentration that modulate actions of heat shock on bovine oocytes during in vitro maturation. Theriogenology 68, 763-70.

Eckert, J. \& Niemann, H. (1995). In vitro maturation, fertilization and culture to blastocysts of bovine oocytes in protein-free media. Theriogenology 43, 1211-25.

Filosa, S., Fico, A., Paglialunga, F., Balestrieri, M., Crooke, A., Verde, P., Abrescia, P., Bautista, J.M. \& Martini, G. (2003). Failure to increase glucose consumption through the pentose-phosphate pathway results in the death of glucose-6-phosphate dehydrogenase gene-deleted mouse embryonic stem cells subjected to oxidative stress. Biochem. J. 370(Pt 3), 935-43.

Gamarra, G., Le Guienne, B., Lacaze, S. \& Ponsart, C. (2011). Bovine IVP embryo speed development in SOF medium does not influence sex ratio: Preliminary results: 152. 27th Annual Meeting A.E.T.E., 09. - 10.09.2011, Chester.

Grant, V.J. \& Chamley, L.W. (2010). Can mammalian mothers influence the sex of their offspring peri-conceptually? Reproduction 140, 425-33.

Greve, T., Callesen, H., Hyttel, P. \& Avery, B. (1994). From oocyte to calf: in vivo and in vitro. Animal Production and Biotechnology. G. F. Greppi \& G. Enne. Paris, Elsevier Biofutur: pp. 71-94.

Gutierrez-Adan, A., Oter, M., Martinez-Madrid, B., Pintado, B. \& De La Fuente, J. (2000). Differential expression of two genes located on the $X$ chromosome between male and female in vitro-produced bovine embryos at the blastocyst stage. Mol. Reprod. Dev. 55, 146-51.

Gutierrez-Adan, A., Lonergan, P., Rizos, D., Ward, F.A., Boland, M.P., Pintado, B. \& de la Fuente, J. (2001). Effect of the in vitro culture system on the kinetics of blastocyst development and sex ratio of bovine embryos. Theriogenology 55, 1117-26.

Gutierrez-Adan, A., Perez-Crespo, M., Fernandez-Gonzalez, R., Ramirez, M.A., Moreira, P., Pintado, B., Lonergan, P. \& Rizos, D. (2006). Developmental consequences of sexual dimorphism during pre-implantation embryonic development. Reprod. Domest. Anim. 41 (Suppl. 2), 54-62.

Gwatkin, R.B. \& Haidri, A.A. (1974). Oxygen requirements for the maturation of hamster oocytes. J. Reprod. Fertil. 37, 127-9.

Hashimoto, S. (2009). Application of in vitro maturation to assisted reproductive technology. J. Reprod. Dev. 55, 1-10.

Hashimoto, S., Minami, N., Takakura, R., Yamada, M., Imai, H. \& Kashima, N. (2000a). Low oxygen tension during in vitro maturation is beneficial for supporting the subsequent development of bovine cumulus-oocyte complexes. Mol. Reprod. Dev. 57, 353-60.

Hashimoto, S., Minami, N., Yamada, M. \& Imai, H. (2000b). Excessive concentration of glucose during in vitro maturation impairs the developmental competence of bovine oocytes after in vitro fertilization: relevance to intracellular reactive oxygen species and glutathione contents. Mol. Reprod. Dev. 56, 520-6.

Helle, S., Laakson, T., Adamsson, A., Paranko, J. \& Huitu, O. (2008). Female field voles with high testosterone and glucose levels produce male-biased litters. Anim. Behav. 75, 1031-9.

Herrick, J.R., Lane, M., Gardner, D.K., Behboodi, E., Memili, E., Blash, S., Echelard, Y. \& Krisher, R.L. (2006). Metabolism, protein content, and in vitro embryonic development of goat cumulus-oocyte complexes matured with physiological concentrations of glucose and L-lactate. Mol. Reprod. Dev. 73, 256-66.

Holm, P., Booth, P.J., Schmidt, M.H., Greve, T. \& Callesen, H. (1999). High bovine blastocyst development in a static in vitro production system using SOFaa medium supplemented with sodium citrate and myo-inositol with or without serum-proteins. Theriogenology 52, 683-700.

Iwamoto, M., Onishi, A., Fuchimoto, D., Somfai, T., Takeda, K., Tagami, T., Hanada, H., Noguchi, J., Kaneko, H., 
Nagai, T. \& Kikuchi, K. (2005). Low oxygen tension during in vitro maturation of porcine follicular oocytes improves parthenogenetic activation and subsequent development to the blastocyst stage. Theriogenology 63, 1277-89.

Iwata, H., Kimura, K., Hashimoto, S., Ohta, M., Tominaga, T. \& Minami, S. (2002). Role of G6PD activity on sex ratio and developmental competence under oxidative stress. J. Reprod. Dev. 48, 447-53.

Jiang, H.S., Wang, W., Lu, K.H., Gordon, I. \& Polge, C. (1992). Examination of cell numbers in blastocysts derived from IVM, IVF, and IVC of bovine follicular oocytes. Theriogenology 37, 229.

Karja, N.W., Kikuchi, K., Fahrudin, M., Ozawa, M., Somfai, T., Ohnuma, K., Noguchi, J., Kaneko, H. \& Nagai, T. (2006). Development to the blastocyst stage, the oxidative state, and the quality of early developmental stage of porcine embryos cultured in alteration of glucose concentrations in vitro under different oxygen tensions. Reprod. Biol. Endocrinol. 4, 54.

Kastrop, P.M., Bevers, M.M., Destree, O.H. \& Kruip, T.A. (1990). Analysis of protein synthesis in morphologically classified bovine follicular oocytes before and after maturation in vitro. Mol. Reprod. Dev. 26, 222-6.

Khurana, N.K. \& Niemann, H. (2000). Energy metabolism in preimplantation bovine embryos derived in vitro or in vivo. Biol. Reprod. 62, 847-56.

Kikuchi, K., Onishi, A., Kashiwazaki, N., Iwamoto, M., Noguchi, J., Kaneko, H., Akita, T. \& Nagai, T. (2002). Successful piglet production after transfer of blastocysts produced by a modified in vitro system. Biol. Reprod. 66, 1033-41.

Kimura, K., Spate, L.D., Green, M.P. \& Roberts, R.M. (2005). Effects of D-glucose concentration, D-fructose, and inhibitors of enzymes of the pentose phosphate pathway on the development and sex ratio of bovine blastocysts. Mol. Reprod. Dev. 72, 201-7.

Kimura, K., Iwata, H. \& Thompson, J.G. (2008). The effect of glucosamine concentration on the development and sex ratio of bovine embryos. Anim. Reprod. Sci. 103, 228-38.

Landau, S., Braw-Tal, R., Kaim, M., Bor, A. \& Bruckental, I. (2000). Preovulatory follicular status and diet affect the insulin and glucose content of follicles in high-yielding dairy cows. Anim. Reprod. Sci. 64, 181-97.

Larson, M.A., Kimura, K., Kubisch, H.M. \& Roberts, R.M. (2001). Sexual dimorphism among bovine embryos in their ability to make the transition to expanded blastocyst and in the expression of the signaling molecule IFN-tau. Proc. Natl. Acad. Sci. USA 98, 9677-82.

Leroy, J.L., Vanholder, T., Delanghe, J.R., Opsomer, G., Van Soom, A., Bols, P.E. \& A. de Kruif, A. (2004). Metabolite and ionic composition of follicular fluid from different-sized follicles and their relationship to serum concentrations in dairy cows. Anim. Reprod. Sci. 80, 20111.

McNatty, K.P. (1978). Follicular Fluid. The Vertebrate Ovary: Comparative Biology and Evolution. R.E.Jones (ed.). University of Michigan, Plenum Press: pp. 215-59.

Morgan, J.F., Campbell, M.E. \& Morton, H.J. (1955). The nutrition of animal tissues cultivated in vitro. I. A survey of natural materials as supplements to synthetic medium 199. J. Natl. Cancer Inst. 16, 557-67.
Morgan, J.F., Morton, H.J. \& Parker, R.C. (1950). Nutrition of animal cells in tissue culture; initial studies on a synthetic medium. Proc. Soc. Exp. Biol. Med. 73, 1-8.

Morton, K.M., Herrmann, D., Sieg, B., Struckmann, C., Maxwell, W.M., Rath, D., Evans, G., Lucas-Hahn, A., Niemann, H. \& Wrenzycki, C. (2007). Altered mRNA expression patterns in bovine blastocysts after fertilisation in vitro using flow-cytometrically sex-sorted sperm. Mol. Reprod. Dev. 74, 931-40.

Orsi, N.M., Gopichandran, N., Leese, H.J., Picton, H.M. \& Harris, S.E. (2005). Fluctuations in bovine ovarian follicular fluid composition throughout the oestrous cycle. Reproduction 129, 219-28.

Oyamada, T. \& Fukui, Y. (2004). Oxygen tension and medium supplements for in vitro maturation of bovine oocytes cultured individually in a chemically defined medium. $J$. Reprod. Dev. 50, 107-17.

Park, J.I., Hong, J.Y., Yong, H.Y., Hwang, W.S., Lim, J.M. \& Lee, E.S. (2005). High oxygen tension during in vitro oocyte maturation improves in vitro development of porcine oocytes after fertilization. Anim. Reprod. Sci. 87, 133-41.

Pavlok, A., Lapathitis, G., Cech, S., Kubelka, M., Lopatarova, M., Holy, L., Klima, J., Motlik, J. \& Havlicek, V. (2005). Simulation of intrafollicular conditions prevents GVBD in bovine oocytes: a better alternative to affect their developmental capacity after two-step culture. Mol. Reprod. Dev. 71, 197-208.

Pinyopummintr, T. \& Bavister, B.D. (1995). Optimum gas atmosphere for in vitro maturation and in vitro fertilization of bovine oocytes. Theriogenology 44, 471-7.

Preis, K.A., Seidel, Jr., G.E. \& Gardner, D.K. (2007). Reduced oxygen concentration improves the developmental competence of mouse oocytes following in vitro maturation. Mol. Reprod. Dev. 74, 893-903.

Rizos, D., Ward, F., Duffy, P., Boland, M.P. \& Lonergan, P. (2002). Consequences of bovine oocyte maturation, fertilization or early embryo development in vitro versus in vivo: implications for blastocyst yield and blastocyst quality. Mol. Reprod. Dev. 61, 234-48.

Rose, T.A. \& Bavister, B.D. (1992). Effect of oocyte maturation medium on in vitro development of in vitro fertilized bovine embryos. Mol. Reprod. Dev. 31, 72-7.

Rose-Hellekant, T.A., Libersky-Williamson, E.A. \& Bavister, B.D. (1998). Energy substrates and amino acids provided during in vitro maturation of bovine oocytes alter acquisition of developmental competence. Zygote 6, 28594.

Rosenfeld, C.S., Grimm, K.M., Livingston, K.A., Brokman, A.M., Lamberson, W.E. \& Roberts, R.M. (2003). Striking variation in the sex ratio of pups born to mice according to whether maternal diet is high in fat or carbohydrate. Proc. Natl. Acad. Sci. USA 100, 4628-32.

Rubessa, M., Boccia, L., Campanile, G., Longobardi, V., Albarella, S., Tateo, A., Zicarelli, L. \& Gasparrini, B. (2011). Effect of energy source during culture on in vitro embryo development, resistance to cryopreservation and sex ratio. Theriogenology 76, 1347-55.

Sato, H., Iwata, H., Hayashi, T., Kimura, K., Kuwayama, T. \& Monji, Y. (2007). The effect of glucose on the progression of the nuclear maturation of pig oocytes. Anim. Reprod. Sci. 99, 299-305. 
Stinshoff, H., Wilkening, S., Hanstedt, A., Bruning, K. \& Wrenzycki, C. (2011). Cryopreservation affects the quality of in vitro produced bovine embryos at the molecular level. Theriogenology 76, 1433-41.

Sutton, M.L., Gilchrist, R.B. \& Thompson, J.G. (2003). Effects of in-vivo and in-vitro environments on the metabolism of the cumulus-oocyte complex and its influence on oocyte developmental capacity. Hum. Reprod. Update 9, 35-48.

Sutton-McDowall, M.L., Gilchrist, R.B. \& Thompson, J.G. (2005). Effect of hexoses and gonadotrophin supplementation on bovine oocyte nuclear maturation during in vitro maturation in a synthetic follicle fluid medium. Reprod. Fertil. Dev. 17, 407-15.

Sutton-McDowall, M.L., Gilchrist, R.B. \& Thompson, J.G. (2010). The pivotal role of glucose metabolism in determining oocyte developmental competence. Reproduction 139, 685-95.

Thompson, J.G., Simpson, A.C., Pugh, P.A., Donnelly, P.E. \& Tervit, H.R. (1990). Effect of oxygen concentration on in-vitro development of preimplantation sheep and cattle embryos. J. Reprod. Fertil. 89, 573-8.

van de Sandt, J.J., Schroeder, A.C. \& Eppig, J.J. (1990). Culture media for mouse oocyte maturation affect subsequent embryonic development. Mol. Reprod. Dev. 25, 164-71.

Wise, T. (1987). Biochemical analysis of bovine follicular fluid: albumin, total protein, lysosomal enzymes, ions, steroids and ascorbic acid content in relation to follicular size, rank, atresia classification and day of estrous cycle. J. Anim. Sci. 64, 1153-69.

Wrenzycki, C., Herrmann, D., Carnwath, J.W. \& Niemann, H. (1998). Expression of RNA from developmentally important genes in preimplantation bovine embryos produced in TCM supplemented with BSA. J. Reprod. Fertil. 112, 387-98.

Wrenzycki, C., Herrmann, D. \& Niemann, H. (2007). Messenger RNA in oocytes and embryos in relation to embryo 760 viability. Theriogenology 68(Suppl. 1), S77-83. 